


\section{Preludios de la independencia. Aportes de jesuitas y agustinos a las reformas educativas neogranadinas del siglo XVIII ${ }^{1}$}

\section{Preludes of the independence. Contributions of jesuits and augustinians to the neo-granadian's educational reforms from XVIII century}

Doi:10.25100/hye.v17i56.11231

Artículo recibido: 07-01-2020. Artículo aceptado: 04-11-2020

\section{Carlos Arnulfo Rojas}

Universidad Surcolombiana (Colombia)

Correo electrónico: carlos.rojas@usco.edu.co

ORCID: https://orcid.org/0000-0001-8367-7049

Forma de citar este artículo: Rojas, Carlos Arnulfo. "Preludios de la independencia: Aportes de jesuitas y agustinos a las reformas educativas Neogranadinas del siglo XVIII". Historia y Espacio, vol. 17, n 56 (2021): 17-44. Doi. org/ 10.25100/hye.v17i56. 11231

1 Este artículo es fruto del proyecto de investigación "Expansión y espiritualidad de la Orden de Agustinos Recoletos en el Nuevo Reino de Granada, siglos XVII y XVIII”, código INV2017E-007, cofinanciado entre la Universitaria Agustiniana y la Universidad Surcolombiana. 


\section{Resumen}

Este artículo trata sobre las reformas educativas emprendidas por los jesuitas y agustinos en sus colegios y universidades a lo largo del siglo XVIII. Valora cómo estas ayudaron no solo a la configuración de una identidad propiamente neogranadina, sino también de base ideológica a los discursos y acciones de los agentes de la independencia de principios del siglo XIX. Así mismo, desarrolla un apartado acerca de la llegada y evolución de la ilustración hispana, puesto que estas se producen en paralelo a la reforma educativa. El artículo se realiza con base enun análisis relacional de la bibliografía secundaria existente tanto de las reformas educativas como de la ilustración neogranadina del siglo XVIII, así como de fuentes primarias.

Palabras claves: reformas educativas, Compañía de Jesús, Orden de San Agustín, ilustración hispana, siglo XVIII.

\section{Abstract}

This article examines the educational reforms carried out by the Jesuits and the Augustinians at their schools and universities throughout the 18th century. It studies not only how these reforms contributed to the configuration of a New Granadan identity, but also how they constituted an ideological basis for the discourses and actions of the agents of independence in the early 19th century. Likewise, the article develops a section on the the arrival and evolution of the Hispanic Enlightenment, which occurred at the same time as the educational reforms. The text is based on a relational analysis of the secondary bibliography concerning the educational reforms and the New Granadan Enlightenment in the 18 th century and on primary sources.

Key words: Educational reforms, Society of Jesus, Order of Saint Augustine, Hispanic Enlightenment, 18th century. 


\section{Carlos Arnulfo Rojas}

\section{Preludios de la independencia. Aportes de jesuitas y agustinos a las reformas educativas neogranadinas del siglo XVIII ${ }^{2}$}

\section{Introducción}

La independencia de la Nueva Granada no fue una coyuntura singular y única aislada de los procesos socioculturales y económicos vividos en este territorio; más bien, es fruto de ellos. En esta medida, los acontecimientos revolucionarios producidos en las primeras décadas del siglo XIX son, en buena medida, resultado de los llevados a cabo a lo largo del siglo XVIII. Las reformas educativas emprendidas por las órdenes regulares de jesuitas y agustinos de la Iglesia católica obrarían como causa epistémica del pensamiento revolucionario, pues posibilitaron el desarrollo de un pensamiento liberado de la esclavitud del silogismo aristotélico tomista que había primado en la educación neogranadina desde el establecimiento de la sociedad colonial y sus instituciones educativas. Esta liberación produciría, por una parte, el nacimiento de una conciencia propiamente neogranadina y, por otra, la base ideológica de los agentes de la independencia.

El problema central de este artículo se encamina a evidenciar el aporte ideológico que las reformas educativas, emprendidas por jesuitas y agustinos en sus colegios y universidades a lo largo del siglo XVIII, tuvieron en el pensamiento y las acciones de los agentes de la independencia neogranadinos de principios del siglo XIX. Así mismo, a demostrar cómo el desarrollo de este pensamiento sirvió de base para la conformación de una identidad americana opuesta a la peninsular; hecho que sería indispensable en la conformación de la identidad colombiana. Finalmente, dado que las reformas educativas coinciden, desde mediados del siglo XVIII, con la llegada y desarrollo de la ilustración hispana a la Nueva Granada, el artículo también expone cómo aquella, aunque en principio buscaba una mayor eficiencia en la explotación de los recursos

2 Este artículo es fruto del proyecto de investigación "Expansión y espiritualidad de la Orden de Agustinos Recoletos en el Nuevo Reino de Granada, siglos XVII y XVIII", código INV2017E-007, cofinanciado entre la Universitaria Agustiniana y la Universidad Surcolombiana. 
naturales del territorio, igualmente sirvió para apuntalar la independencia jurídica y afianzar la identidad neogranadina.

Para el desarrollo del objeto de estudio de este artículo se realizó un análisis relacional de la bibliografía existente acerca de las reformas educativas y la ilustración neogranadina del siglo XVIII; de manera general, se analizaron los aportes teóricos e historiográficos de los trabajos de Rafael Gómez Hoyos, Renán Silva, Diana Soto Arango, Víctor Manuel Uribe, Rodrigo Hernán Torrejano Vargas y Fernando Betancourt Serna; mientras que en el caso específico de los colegios y universidades jesuitas, los escritos de Juan Manuel Pacheco, José del Rey Fajardo y Ricardo Cobos; en tanto que de los agustinos, los trabajos de Fernando Campo del Pozo. Esta metodología permitió encontrar relaciones nuevas e inesperadas entre el periodo de las reformas educativas, la ilustración hispana y los procesos de independencia neogranadinos. Así mismo, constatar cómo la base ideológica de los agentes de la independencia se fue fraguando incluso antes de la llegada del movimiento ilustrado a la Nueva Granada.

El artículo consta de cuatro partes. La primera se destina a retratar el estado de la educación superior en la Nueva Granada a lo largo del periodo colonial, haciendo énfasis en las postrimerías del siglo XVIII; la segunda, a explicar las reformas educativas introducidas por la Compañía de Jesús en sus colegios y universidades antes de su expulsión; la tercera, a las modificaciones formativas que la Orden de San Agustín realizó en sus colegios y universidades; y la cuarta, a valorar la conformación del pensamiento ilustrado neogranadino como base ideológica de los agentes de la independencia de los territorios que conformarían la República de Colombia.

\section{La educación superior en el Nuevo Reino de Granada}

Durante el periodo colonial, la Nueva Granada careció de universidades públicas de la forma como existieron en los virreinatos de Nueva España y Perú3. Contó solamente con dos universidades privadas en Santafé: la Universidad Santo Tomás y la Universidad Javeriana, fundadas en 1580 y 1622 y administradas por la Orden de Predicadores y la Compañía de Jesús respectivamente ${ }^{4}$. De

3 Un primer acercamiento a este tema puede verse en Carlos Arnulfo Rojas Salazar, "Amos del oro, siervos del rey, ciudadanos del reino. La elite de Popayán y los procesos de independencia hispanoamericanos, 1808-1820” (tesis doctoral, Universidad de Salamanca, 2015), 161-179.

4 Para la historia de la fundación de las Universidades Santo Tomás y Javeriana, véase respectivamente Álvaro Gálvez Ramírez, Universidad Santo Tomás. 1580-1980.400 años (Bogotá: 
acuerdo con la clasificación de las instituciones superiores presentadas en la Recopilación de Leyes de Indias, estas dos universidades tenían facultades restringidas, por lo tanto, más reducidas que las de México y Lima ${ }^{5}$.

Desde sus inicios, las universidades santafereñas contaron con la Facultad de Artes y Filosofía y la de Teología, en las que se instruyó casi exclusivamente a miembros de las órdenes religiosas; además, algunas veces, tuvieron facultades de Jurisprudencia ${ }^{6}$ y Medicina ${ }^{7}$, en las que formaron a varios seglares. Por otra parte, más que centros de enseñanza propiamente dichos, las dos universidades santafereñas fueron tribunales evaluadores, puesto que los alumnos recibían su educación en los Colegios Mayores de San Bartolomé y Nuestra Señora del Rosario $^{8}$ y, posteriormente, pasaban a ellas a examinarse para la obtención de las titulaciones superiores. En 1767, cuando la Compañía de Jesús fue expulsada de la Nueva Granada, la capacidad de evaluar y expedir títulos quedó en potestad exclusiva de la Universidad Santo Tomás ${ }^{9}$, que la conservó como un monopolio hasta que fueron creadas las primeras universidades republicanas en Colombia ${ }^{10}$.

Universidad Santo Tomás, 1980) y Juan Manuel Pacheco, S. J., Los jesuitas en Colombia (Bogotá: Editorial San Juan Eudes, 1959).

5 Recopilación de leyes de los reynos de las Indias: mandadas a imprimir y publicar por la magestad católica del rey Don Carlos II, nuestro señor, Tomo I, Libro I, Título Vientidós, De las Universidades y estudios generales y particulares de las Indias (Madrid: Julián de Paredes 1681), fols. 110-121.http://www.gabrielbernat.es/espana/leyes/rldi/rldi.html.

6 Sobre la formación en derecho, véase Jorge Tomás Uribe Ángel, Historia de la enseñanza en el Colegio Mayor del Rosario, 1653-1767 (Bogotá: Centro Editorial de la Universidad del Rosario, 2003), 143-154; Víctor Manuel Uribe-Urán, Vidas honorables: abogados, familias y políticas en Colombia (Medellín: Fondo Editorial Universidad Eafit, 2008), 81-107.

7 Guillermo Hernández de Alba, Aspectos de la cultura en Colombia (Bogotá: Biblioteca Popular de Cultura Colombiana, 1947), 107-113; Emilio Quevedo y Camilo Duque, Historia de la cátedra de medicina. 1653-1865 (Bogotá: Centro Editorial de la Universidad del Rosario, 2002), 5-9.

8 Los niveles educativos de la Nueva Granada colonial se dividieron en: 1) la escuela de primeras letras; 2) los estudios menores, que comprendían gramática, humanidades y retórica ; 3) artes y filosofía; 4) cánones y teología; 5) jurisprudencia; y 6) medicina.

9 Diana Soto Arango, Mutis educador de la élite neogranadina (Tunja: Universidad Pedagógica y Tecnológica de Colombia, 2005), 52; Uribe-Urán, Vidas honorables, 87.

${ }^{10}$ Las tres primeras universidades públicas de la Gran Colombia fueron creadas por la Ley del 18 de marzo de 1826, fundadas en Bogotá, Caracas y Quito. Véase Hernández de Alba, Aspectos, 49-56; Diana Soto Arango, "Aproximación histórica a la Universidad colombiana", Revista Historia de la Educación Latinoamericanas, No.7 (2005): 110-113. 
Tanto el Colegio Seminario de San Bartolomé, fundado por los jesuitas en $1605^{11}$, como el Colegio Mayor de Nuestra Señora del Rosario, instituido por los dominicos en $1653^{12}$, fueron los centros de enseñanza superior propiamente dichos en los que se formaron las elites neogranadinas, eclesiástica y civil, durante el periodo colonial. Hacia uno de estos dos claustros se desplazaron, desde las distintas ciudades y provincias, los hijos de burócratas, comerciantes, mineros y terratenientes, creando en ellos verdaderas redes de camarillas, amistades y lazos de compadrazgos, las cuales repercutieron profundamente en la vida política neogranadina a través de un sistema de favoritismos, privilegios e influencias ${ }^{13}$. Cabe decir que, además de estos colegios y universidades, en Santafé también se estableció el Convento-Universidad de San Nicolás de Bari, administrado por la Orden de San Agustín y destinado a la formación de los miembros de esta orden. De igual manera, en el Virreinato se fundaron los Colegios Mayores de San Luis y San Fernando y las Universidades de San Gregorio Magno y Santo Tomás en la ciudad de Quito, pertenecientes a jesuitas y dominicos respectivamente ${ }^{14}$. En estas instituciones adquirieron titulaciones superiores neogranadinos procedentes dela presidencia de Quito y algunos originarios de la gobernación de Popayán, dado que gozaban de las mismas prerrogativas que las universidades de Santafé. Finalmente, en el Virreinato santafereño existieron los colegios-seminarios provinciales, como fueron los de Panamá, Cartagena y Popayán, en los que también se ofrecieron estudios

${ }^{11}$ Para la historia del Colegio Mayor de San Bartolomé véase Daniel Restrepo, El Colegio de San Bartolomé I. El colegio a través de nuestra historia (Bogotá: Sociedad editorial, 1928); William Jaramillo Mejía, Real Colegio Mayor y Seminario de San Bartolomé — nobleza e hidalguía-. Colegiales de 1605 a 1820 (Bogotá: Instituto Colombiano de Cultura Hispánica, 1996).

${ }^{12}$ Para la historia del Colegio Mayor de Nuestra Señora del Rosario véase Guillermo Hernández de Alba, Crónica del muy ilustre Real Colegio Mayor de Nuestra Señora del Rosario, 2 vols. (Bogotá: Editorial Centro, 1938); María Clara Guillén de Iriarte, Nobleza e hidalguía en el Nuevo Reino de Granada. Colegio Mayor de Nuestra Señora del Rosario, Tomos I y II (Santafé de Bogotá: Ediciones Rosaristas, 1994).

${ }^{13}$ Renán Silva, Los ilustrados de Nueva Granada. Genealogía de una comunidad interpretativa, 2. ed. (Medellín: Fondo Editorial Universidad Eafit - Banco de la República, 2008), 38.

${ }^{14}$ Estos colegios y universidades también pertenecieron a jesuitas y dominicos respectivamente. Con la expulsión de los jesuitas en 1767, las Universidades de San Gregorio Magno y Santo Tomás se fusionaron en un solo claustro universitario, que desde 1788 pasó a llamarse Universidad Pública de Santo Tomás. 
superiores en filosofía y teología. De estos colegios, solo el de Popayán confirió títulos superiores durante un corto tiempo en el último cuarto del siglo XVIII ${ }^{15}$.

El acceso a los colegios y universidades neogranadinas se realizaba una vez los estudiantes probaban su pureza racial - no tener mezcla de sangre con las castas-, sus antecedentes religiosos - no tener vinculación morisca o judaica-, la legitimidad de su nacimiento - no ser hijo natural-y la pertenencia a una familia honorífica - descender de algún conquistador o hijodalgo ${ }^{16}$ - . Así, la educación superior neogranadina fue un privilegio de los miembros de las elites. A pesar de esta realidad, la población universitaria creció de manera constante a lo largo del siglo XVIII. Primero, de manera lenta, desde la década de $1740 \mathrm{y}$, posteriormente, a partir de la década de 1770 , de forma acelerada ${ }^{17}$. En 1787 el arzobispo-virrey Caballero y Góngora afirmó que en los colegios de Santafé abundaban los discípulos provenientes de las gobernaciones de Cartagena, Popayán y Antioquia ${ }^{18}$. De 1770 a 1790, Renán Silva contabilizó veintitrés colegiales provenientes de la gobernación de Popayán de los noventa que cursaban jurisprudencia en el Colegio Mayor de Nuestra Señora del Rosario $^{19}$. Algo parecido sucedió en el Colegio de San Bartolomé, aunque en menor medida, pues, mientras cincuenta payaneses decidieron estudiar en el Rosario entre 1756 y 1815, tan solo diecinueve lo hicieron en San Bartolomé. Posiblemente las familias payanesas prefirieron el primer colegio debido a que los jesuitas abandonaron la administración del segundo tras su expulsión del Virreinato en 1767.

La Iglesia católica, a través del clero regular, monopolizó la enseñanza en las universidades y colegios del Virreinato neogranadino, en la que instruía en los preceptos morales de los textos bíblicos y el silogismo escolástico. No obstante, la filosofía escolástica fue perdiendo espacio en los colegios y universidades de algunas órdenes religiosas, como fue el caso de la Compañía de Jesús y la Orden de San Agustín, que decidieron introducir métodos y contenidos de enseñanza moderna sin que ello significara el abandono de los principios cristianos, aunque sí en contra del sistema formativo peripatético y silogístico, que se llevaba a cabo en los colegios y universidades de la Orden de Predicadores.

\footnotetext{
${ }^{15}$ Renán Silva, Universidad y sociedad en el Nuevo Reino de Granada (Santafé de Bogotá: Banco de la República, 1992), 31; Uribe-Urán, Vidas honorables, 86.

${ }^{16}$ Uribe-Urán, Vidas honorables, 84-85.

${ }^{17}$ Silva, Los ilustrados, 46.

${ }^{18}$ Silva, 40.

${ }^{19}$ Silva, 43.
} 
Si bien los planes de educación superior sufrieron modificaciones a lo largo del siglo XVIII, principalmente desde la década de 1730-1740, solo fue hasta la segunda mitad de esta centuria cuando se adoptaron transformaciones trascendentales. Durante la década de 1760-1770 se dieron dos acontecimientos importantes que ayudaron a la modernización de la educación en la Nueva Granada ${ }^{20}$. El primero fue la consolidación de las apuestas educativas emprendidas por la Compañía de Jesús y la Orden de San Agustín en sus respectivos colegios y universidades a lo largo de las décadas anteriores del siglo XVIII, y el segundo, la llegada del movimiento ilustrado de la mano de los funcionarios de Carlos III ${ }^{21}$.

\section{La reforma educativa en los colegios jesuitas en el siglo XVIII}

Desde su llegada al Nuevo Reino los jesuitas apostaron por establecerse en las ciudades y provincias que consideraron vitales para sus actividades educativas y misionales. Así, aseguraron su presencia fundando colegios o estableciendo misiones en Cartagena y Santafé en 1604; Tunja, en 1611; Honda, en 1620; Pamplona y Chita, en 1625; Mérida, en 1628; Popayán, en 1640; Mompox, en 1643, y Santo Tomé de Guayana, en 1646. En el siglo XVIII se expandieron a Pasto, en 1712; Antioquia, en 1727, y Buga, en $1745^{22}$. Con esta red de colegios los jesuitas asumieron casi en forma de monopolio ${ }^{23}$, compartido en menor medida con la Orden de Predicadores, la educación de las juventudes neogranadinas en todos sus niveles, produciendo un tipo de cultura que trató de conciliar las creencias cristianas y tradicionales con descubrimientos científicos y la evolución del pensamiento filosófico ${ }^{24}$. Los fines de la educación jesuita se expresaron en los numerales 376 y 381 del reglamento interno de sus colegios. El primero, indicaba que la educación debía llevar al conocimiento y amor de

${ }^{20}$ Silva, 30.

${ }^{21}$ Otros autores han visto en la inauguración de la cátedra de matemáticas de Mutis y la expulsión de los jesuitas del Nuevo Reino los dos acontecimientos trascendentales de esta década. Véase Rodrigo Hernán Torrejano Vargas, "Perfil de la educación universitaria colonial a finales del siglo XVIII”, Revista Diálogo de Saberes, n. ${ }^{\circ} 31$ (2009): 284.

22 José del Rey Fajardo, La enseñanza de las humanidades en los colegios jesuíticos neogranadinos (1604-1767) (Bogotá: Pontificia Universidad Javeriana, 2005), 9.

${ }^{23}$ De los catorce colegios que había en la Nueva Granada diez era regentados por la Compañía de Jesús. Véase Pedro Vargas Sáez, Historia del Real Colegio y Seminario de San Francisco de Asís de Popayán (Popayán: Editorial ABC, 1945), 462.

${ }^{24}$ Del Rey Fajardo, La enseñanza de las humanidades, 51-52. 
Dios, por lo que además de las letras, los alumnos debían aprender la conducta de un buen católico. Mientras el segundo señalaba que, aparte de lo religioso y literario, la educación debía abarcar lo social, patriótico y físico ${ }^{25}$. De esta manera, se buscaba la formación de ciudadanos probos, honestos y virtuosos ${ }^{26}$. A comienzos del siglo XVII, cuando la Nueva Granada entró en la órbita de la Compañía de Jesús, esta ya había establecido sus directrices educativas a través de tres documentos: El Directorium de los ejercicios espirituales de su fundador Ignacio de Loyola, la Ratio atque institutio studiorum Societatis Iesu y el cuerpo de instrucciones y normas que regulaban la vida interna y externa de la Orden. Estos tres textos rigieron todas las instituciones educativas jesuitas durante los siglos XVII y XVIII ${ }^{27}$.

La Ratio atque institutio studiorum Societatis Iesu o, simplemente Ratio Studiorum, aprobada definitivamente en 1599, fue el texto más importante para la educación jesuita, dado que rigió la conducta de sus colegios en Europa, América y Asia hasta la extinción de la Compañía de Jesús en el siglo XVIII. Fue ante todo un plan de estudios con una metodología dirigida al dominio del latín, para adentrarse luego en las obras latinas. Así, todo lo que no fuera latín tenía un carácter secundario en ella. La geografía y la historia se aprendían anexas a las lecturas de los textos latinos, mientras que las matemáticas y física no se cursaban durante los estudios menores, sino hasta el ciclo filosófico. La extrema importancia concedida al latín en la Ratio Studiorum se explica por dos razones. La primera, porque era la lengua utilizada por la diplomacia internacional de entonces, y la segunda, porque todos los tratados importantes de teología, filosofía y ciencia se escribían en ella ${ }^{28}$. Para los jesuitas era indispensable que sus alumnos escribiesen y hablasen correctamente en este idioma.

En la Nueva Granada, como en el resto del mundo, la labor educativa jesuita encontró sus singularidades, por tal razón fue necesario adaptar el aparato conceptual de la Ratio a las realidades concretas del territorio ${ }^{29}$. La Praxis de los Estudios Mayores y Menores, del colegio jesuita de San Luis de Quito, fue el documento encargado de adecuar la Ratio a un contexto específicamente

${ }^{25}$ Ricardo Cobos, La formación intelectual en los colegios de la Compañía de Jesús (Madrid: Dirección General de Enseñanza Media, s/f), 7

${ }^{26}$ Del Rey Fajardo, La enseñanza de las humanidades, 41.

${ }^{27}$ Del Rey Fajardo, La enseñanza de las humanidades, 13.

${ }^{28}$ Cobos, La formación intelectual, 8-9.

${ }^{29}$ José del Rey Fajardo y Germán Marquínez Argote, La enseñanza de la filosofía en la Universidad Javeriana colonial (1623-1767) (Bogotá: Pontificia Universidad Javeriana, 2010), 18. 
neogranadino. Especialistas sobre el tema consideran que esta Praxis fue aplicada, con algunas variaciones mínimas, en todos los colegios de la provincia de Santafé y Quito de la Compañía de Jesús ${ }^{30}$. La Praxis vio la luz pública el 15 de abril de 1666, luego de haber sido examinada detalladamente por el rector, consultores y maestros del colegio de Quito ${ }^{31}$.

Tanto la Ratio como la Praxis determinaban cinco años para los estudios menores realizados en los colegios: Ínfima, Media, Suprema, Humanidades y Retórica. De estos, los tres primeros se dedicaban al aprendizaje de la gramática; el cuarto, a la progresiva adquisición de erudición y, el quinto, a la elocuencia. Los textos fundamentales con los que se formaban los alumnos durante esta etapa fueron la gramática del P. Manuel Álvarez, la Retórica del P. Mario Soares, la Retórica de Cicerón y, finalmente, la Retórica y Poética de Aristóteles. La estructura de los colegios jesuitas se reducía al mínimo requerido para lograr sus fines formativos, y descansaba principalmente sobre cuatro personajes: el rector, responsable de la vida escolar local; el profesor de gramática, quien atendía constantemente las aulas; el procurador, que administraba la financiación de la institución; y el prefecto de iglesia, encargado de fomentar la vida cristiana entre el alumnado ${ }^{32}$.

En este sentido organizacional educativo, las universidades ofrecían la formación superior. Así, la carrera filosófica en la Universidad Javeriana se extendía por tres años. En el primero se enseñaba lógica, en el segundo, física y en el tercero, metafísica. Se acostumbraba que el curso empezara cada tres años y que un catedrático acompañara a un grupo de alumnos durante todos los años de su formación. El texto y centro fundamental de la enseñanza era el de Aristóteles, que se explicaba desde sus comentaristas más célebres. Entretanto, la carrera de teología abarcaba cuatro años. En los dos primeros se enseñaba teología dogmática, en el tercero, teología moral y en el cuarto,

30 "Praxis de los estudios para el colegio de Quito sacada de varias órdenes que han dejado acerca de esto el P. Rodrigo Figueroa Visitador y los padres provinciales de esta provincia; los cuales han reducido a método el P. Hernando Cavero provincial de ella, habiéndolos primero consultado con el padre rector y sus consultores y con los maestros de este colegio, Quito 15 de abril de 1666”, en Historia de la Compañía de Jesús en la Antigua Provincia de Quito: 1570-1774, ed. José Jouanen (Quito: Editorial Ecuatoriana, 1941), 569-593.

${ }^{31}$ José Jouanen, ed., Historia de la Compañía de Jesús en la Antigua Provincia de Quito: 1570-1774 (Quito: Editorial Ecuatoriana, 1941), 569.

${ }^{32}$ Del Rey Fajardo, La enseñanza de las humanidades, 77, 92-94. 
Sagradas Escrituras. Las asignaturas eran impartidas por cuatro catedráticos diferentes. La carrera de derecho civil no hacía parte de la docencia ordinaria de la Compañía; sin embargo, algunas de sus universidades en Hispanoamérica la brindaron. En Santafé se creó la Facultad de Cánones y Leyes en la Universidad Javeriana el 13 de junio de $1706^{33}$. Así mismo, la carrera de medicina fue durante mucho tiempo una utopía en la Nueva Granada, aunque cuando se contaba con la presencia de un médico respetable queabría al público, mas casi siempre se careció de un personaje con estas características en el Virreinato ${ }^{34}$.

Por otra parte, la forma de enseñanza en la Universidad Javeriana siguió desde la primera mitad del siglo XVII los escritos del jesuita Francisco Suárez $z^{35}$, que proporcionaron mayor libertad de pensamiento y un método expositivo analítico-sintético frente a la tradicional escolástica del silogismo practicada en la Universidad Santo Tomás ${ }^{36}$. Tal como lo señaló Mario Hernández Sánchez Barba, en la Universidad Javeriana se incubó el humanismo jesuítico que se encaminó al desarrollo de una ilustración política y literaria propiamente americana, la cual desencadenó tanto el pensamiento independentista neogranadino como la crítica a la realidad económica del territorio ${ }^{37}$.

Este humanismo se afianzaría con fuerza a lo largo del siglo XVIII, ayudando a perfeccionar la conciencia americana frente a la europea en las primeras generaciones de criollos ilustrados. No en vano el jesuita Rafael Gómez Hoyos escribiría que "el día en que se publiquen todos los opúsculos y tratados de nuestros profesores universitarios de la Colonia... aparecerá el puesto de honor que Suárez ocupó en nuestras aulas universitarias"38.

Se pueden apreciar tratados como Physica specialis et curiosa, defendido en la Universidad Javeriana en 1755, en el que se combina la antigua filosofía aristotélica con la nueva ciencia moderna. En él, su autor desconocido,

${ }^{33}$ La Real Cédula que autorizó a la academia javeriana a impartir estos estudios fue expedida el 25 de noviembre de 1704. Véase Del Rey Fajardo, 53.

${ }^{34}$ La cátedra de medicina tuvo una corta duración en la Universidad Javeriana. Habiéndose iniciado el 1.ํㅡㄹ de abril de 1636, no tenía alumnos ya para 1641. Véase Del Rey Fajardo, 75.

35 Juan Manuel Pacheco, Los jesuitas en Colombia, Tomo I (1567-1654) (Bogotá: Editorial San Juan Eudes, 1959), 559-560.

${ }^{36}$ Del Rey Fajardo y Marquínez Argote, La enseñanza de la filosofia, 17.

${ }^{37}$ José del Rey Fajardo, Expulsión, extinción y restauración de los jesuitas en el Nuevo Reino de Granada (1767-1815) (Bogotá: Pontificia Universidad Javeriana, 2014), 53-54.

${ }^{38}$ Rafael Gómez Hoyos, La revolución granadina de 1810. Ideario de una generación y una época, Tomo I-1781-1821 (Bogotá: Editorial Temis, 1962), 141. 
menciona filósofos como Descartes, Newton, Hobbes y Spinoza, representantes del pensamiento científico positivista occidental, lo que constata el interés por el estudio de las ciencias útiles en el Virreinato neogranadino, incluso antes de la llegada de José Celestino Mutis ${ }^{39}$. Por otra parte, la influencia de Suárez también se puede percibir en el derecho indiano, sobre todo en su concepción de igualdad jurídica. Así, sus escritos sobre la igualdad de los hombres en su origen, destino, obligaciones y derechos van a cimentar las reclamaciones americanas frente al mundo europeo a finales del siglo XVIII y principios del $\mathrm{XIX}^{40}$. De igual manera, tanto su idea de la naturaleza sociable del hombre en el origen del Estado como la traslación de la potestad de la comunidad política al monarca y su correspondiente reversibilidad en casos de injusticia serán fundamentales en las declaraciones unilaterales de independencia americana. El 2 de abril de 1767, a través de una pragmática, Carlos III determinó que la Compañía de Jesús debía abandonar todos sus dominios. En Santafé, el virrey Messía de la Cerda recibió la notificación real el 7 de julio de 1767, y la cumplió el 1. ${ }^{\circ}$ de agosto siguiente al reclamar el Colegio Máximo, el Seminario de San Bartolomé y el Noviciado de las Nieves a la Compañía de Jesús. En menos de tres meses los jesuitas habían desaparecido del Nuevo Reino ${ }^{41}$. Tras la expulsión de la Compañía de Jesús, los planes de estudios comenzaron a ser transformados en la Nueva Granada, prestando especial atención a la implementación de una educación pública ${ }^{42}$. De acuerdo con la tendencia vanguardista de la formación jesuita a lo largo de los primeros tres cuartos del siglo XVIII, se puede afirmar que, de no haber sido expulsados del Nuevo Reino, los jesuitas hubiesen contribuido no solo a consolidar la conciencia criolla americana, sino también a afianzar las reformas educativas emprendidas por algunos agentes ilustrados del Estado colonial a finales de ese siglo ${ }^{43}$.

39 Juan Manuel Pacheco, Los Jesuitas en Colombia, Tomo III (1696-1767) (Bogotá: Universidad Javeriana, 1989), 444-449.

${ }^{40}$ Del Rey Fajardo, Expulsión, extinción, 53.

${ }^{41}$ José Manuel Groot, Historia eclesiástica y civil de la Nueva Granada (Bogotá: Editorial Cosmos, Biblioteca de Autores Colombianos, 1956), 104-120.

${ }^{42}$ Torrejano Vargas, "Perfil de la educación”, 284.

${ }^{43}$ En el último año que los jesuitas tuvieron a cargo el colegio de Popayán se graduaron de maestros Vicente Olave, Tomas Ruiz Quijano, José Ruz Quijano, José Joaquín Ortiz Nagle, Francisco Antonio Balcázar, José Joaquín Mosquera y Figueroa, José María Mosquera y Figueroa, Ignacio Tenorio Carvajal y Francisco José Arboleda; quienes desempeñaron papeles importantes durante las guerras de independencia, especialmente en defensa de las instituciones monárquicas. Véase Carlos Arnulfo Rojas Salazar, "Educación y ciencia 


\section{La reforma educativa en los colegios agustinianos en el siglo XVIII}

Desde la reforma de la Orden de San Agustín en el siglo XIII, los centros de formación agustinianos contaron con una Ratio Studiorum que regía los contenidos y métodos de enseñanza con los que se educaba a los frailes en los centros de enseñanza de la Orden. No obstante, fue durante el siglo XVI cuando los agustinos decidieron modernizar su ratio educativa. Así, tanto en 1551 como en 1581 precisaron varios aspectos de la formación de novicios y la obtención de títulos, de acuerdo con lo que se había convenido en el Concilio de Trento. No obstante, solo fue hasta el siglo XVIII cuando los colegios agustinianos modernizaron profundamente los contenidos y el método de enseñanza, bajo la tutela de fray Juan Lorenzo Berti ${ }^{44}$. Este italiano se encargó de publicar varios textos que sirvieron de guía para las cátedras que se impartían en los colegios y universidades de la Orden, así como de defender las tesis agustinianas respecto a la gracia y la libertad ${ }^{45}$. Por ejemplo, Berti escribió De Theologicis Disciplinis, texto en el que expuso las enseñanzas teológicas de San Agustín; igualmente redactó Agustiniano Systema de Gratia y La historia eclesiástica. Estas obras ayudaron a la renovación de los centros de enseñanza de la Orden, aunque causaron controversias por su cercanía a las ideas de predestinación defendidas por la corriente jansenista.

Siguiendo las orientaciones de Berti, fray Francisco Javier Vázquez se encargó de reorganizar los estudios impartidos en los colegios y universidades agustinianas en 1753. Aunque Vázquez había nacido en San Miguel de Cajamarca, Perú, tuvo gran protagonismo dentro de la Orden Agustiniana. Sus escritos se encaminaron a introducir la nueva filosofía que exaltaba el método experimental propagado por la corriente ilustrada y, al mismo tiempo, rechazaba la filosofía tradicional y el método escolástico enseñados en las universidades dominicas ${ }^{46}$. Estas ideas de avanzada encontraron eco principalmente en

en la ciudad de Popayán antes de los procesos de independencia hispanoamericanos”, en De imperios a naciones en el mundo ibérico, eds. Alberto Baena Zapatero y Izaskun Álvarez Cuartero (Madrid: Ediciones Doce Calles, 2019), 77.

${ }^{44}$ Fernando Campo del Pozo, "Las reformas universitarias en los agustinos durante la época colonial en Latinoamérica”, en Estudios sobre la universidad latinoamericana. De la colonia al siglo XXI, eds. Diana Soto Arango, Manuel Lucena Samoral y Carlos Rincón (Tunja: Universidad Pedagógica y Tecnológica de Colombia, 2004), 17.

${ }^{45}$ Negrín Fajardo y Ciordia Vergara, La educación como dimensión práctica: una respuesta histórica (Madrid: Editorial Universitaria Ramón Areces, 2010), 117.

${ }^{46}$ Campo del Pozo, "Las reformas universitarias", 18. 
América hispana, en los colegios y universidades de Lima, Quito y Santafé de Bogotá.

Las primeras observaciones que el padre Vázquez realizó se encaminaron a introducir la obligatoriedad de cursar las disciplinas teológicas y la historia eclesiástica de Juan Lorenzo Berti en los centros de formación de la Orden. Además de estas dos cátedras, Vázquez estaba convencido de la importancia de establecer como ineludibles las de oratoria sagrada y astronomía. Con ello, pretendía que los frailes agustinos tuviesen una educación integral en la que pudieran compatibilizar la formación teórica con la práctica, y la filosofía moderna con la teología positivista ${ }^{47}$. Todo esto siguiendo esencialmente los escritos de San Agustín, aunque también la Biblia, los padres de la Iglesia, las enseñanzas de los concilios y los decretos de los papas.

Estas primeras ideas fueron plasmadas ordenadamente en las instrucciones que el propio Vázquez elaboró para la Orden el 1.ํ de agosto de 1771. En ellas aspiraba a que la teoría se uniera a la práctica de acuerdo no solo con los descubrimientos y avances del conocimiento empírico, sino también con la teología agustiniana; a desarrollar una metodología especulativa-práctica y, finalmente, a desplegar una disposición apologética por si se presentaban controversias respecto al conocimiento de las Sagradas Escrituras y la tradición de la Iglesia, contenida en las enseñanzas de los concilios ecuménicos y los escritos de doctores y padres de la Iglesia ${ }^{48}$.

El 18 de agosto de 1773, el padre visitador de la provincia de Nuestra Señora de la Gracia, Juan Bautista González, ordenó "que del todo se quite de las escuelas aquellas cuestiones de la Filosofía y la Teología peripatéticas llenas de cuestiones inútiles y cavilosas, que no sirven para otra cosa que para perder el tiempo"; con ello, las universidades y los colegios agustinianos empezaron a implantar la reforma educativa ilustrada en la Nueva Granada ${ }^{49}$. Las disposiciones del padre visitador fueron recogidas en el capítulo provincial, celebrado en Santafé de Bogotá el 1. ${ }^{\circ}$ de julio de 1776, en el que se acordó que los frailes agustinos debían cursar tres años de filosofía y cinco de teología,

\footnotetext{
${ }^{47}$ Campo del Pozo, 21-22.

${ }^{48}$ Fernando Campo del Pozo, "Modernización de los estudios agustinianos en Santafé de Bogotá por fray Diego Francisco Padilla a finales del siglo XVIII", Revista Historia de la Educación Latinoamericana, N. 2 (2000): 41 .

${ }^{49}$ Campo del Pozo, "Las reformas universitarias", 22.
} 
guiados por los textos de Juan Lorenzo Berti y por un método que permitiera el verdadero progreso de los estudiantes ${ }^{50}$.

El padre Diego Padilla fue una de las figuras agustinianas más sobresalientes en la Nueva Granada, pues se encargó de introducir las reformas educativas en la Universidad San Nicolás de Bari y el Colegio de San Miguel de Santafé. Siguiendo los escritos de fray Vázquez, consideró que era necesario que los novicios se formaran en la filosofía moderna y en los enciclopedistas franceses, siempre y cuando sus enseñanzas no contradijeran el corpus teológico cristiano ${ }^{51}$. Así, el padre Padilla, por una parte, enseñaba los principios dogmáticos del cristianismo y, por otra, la ciencia moderna de la ilustración y el enciclopedismo francés. Ejemplo de esto fueron sus clases del sistema copernicano, física y matemática newtoniana, así como los temas astronómicos $^{52}$. El padre Padilla también tradujo el Tratado de economía política de Rousseau y, aunque difirió en algunos de sus apartados, no obstante, se preocupó por difundir los relacionados con aspectos educativos ${ }^{53}$. De hecho, él mismo los puso en práctica en la escuela de primeras letras que fundó en Bojacá; la cual estuvo abierta a todas las clases sociales. En ella introdujo las ciencias modernas a través de métodos innovadores ${ }^{54}$. De esta manera, este agustino se preocupó por conciliar la fe católica con la cultura moderna y por defender los derechos humanos en la Nueva Granada.

Otro ejemplo de lo avanzado en materia educativa de la Orden de San Agustín fue fray Antonio Noguera. A finales del siglo XVIII, este fraile agustino ostentaba la cátedra de matemáticas y defendía la teoría copernicana en la Universidad San Nicolás de Bari, en contra de la filosofía peripatética y la teoría geocéntrica enseñadas por los dominicos en sus colegios ${ }^{55}$. De hecho, fue tan avanzada la apuesta de la Orden agustiniana por la ciencia moderna que en 1801 solicitó permiso al virrey para discutir públicamente las teóricas copernicanas en su convento, puesto que hasta entonces solo se habían debatido en ambientes privados. Tal como lo aclaró Diana Soto, la controversia por la enseñanza del sistema copernicano se prolongó en el Nuevo Reino hasta

\footnotetext{
${ }^{50}$ Campo del Pozo, "Modernización de los estudios", 41

${ }^{51}$ Campo del Pozo, 38.

${ }^{52}$ Campo del Pozo, 48.

${ }^{53}$ Gómez Hoyos, La revolución granadina, 315-316.

${ }^{54}$ Campo del Pozo, "Modernización de los estudios", 42.

${ }^{55}$ Campo del Pozo, "Las reformas universitarias", 20.
} 
principios del siglo XIX, cuando Mutis, apoyado en los padres agustinos, realizó un informe sucinto en el que dejó claro tanto la universalidad de la enseñanza de este sistema astronómico como su no contradicción con los textos bíblicos y la tradición cristiana ${ }^{56}$.

Así como los jesuitas habían sido hasta 1776 la fuerza impulsora de la conciencia criolla neogranadina, a través de una educación racional y positiva, los agustinos tomaron su testigo y los relevaron en este esfuerzo, sobre todo a partir del último cuarto del siglo XVIII. Aunque su poder hacendístico y educativo no fue nunca comparable al de aquellos, sí lograron influir en un grupo selecto de criollos que desempeñaron papeles destacables en los procesos de independencia neogranadinos. Es el caso del mismo padre Padilla, o del padre provincial de la orden, fray José Chavarría, quienes fueron redactor y firmante, respectivamente, del acta santafereña del 20 de julio de 1810; así mismo, Padilla fue autor del manifiesto titulado: Motivos que han obligado al Nuevo Reino de Granada a reasumir los derechos de soberanía, y miembro encargado de asuntos religiosos de la primera Junta Superior de Gobierno que se creó en Santafés7. A diferencia de la Orden de Predicadores, jesuitas y agustinos dieron paso a las nuevas ideas de la ilustración hispana en sus claustros, colegios y universidades, potencializando desde mediados del siglo XVIII el despertar y actuar de una conciencia política y económica propiamente neogranadina.

\section{Desarrollo de la Ilustración en la Nueva Granada}

El movimiento ilustrado introducido por los Borbones en la España peninsular también se extendió a los territorios americanos. La Ilustración llegó a América y, concretamente al Virreinato neogranadino, a través de los funcionarios públicos, clérigos, miembros de la comisión mineralógica y la expedición botánica que se habían educado bajo sus principios en Europa y pasaron a hacer las Américas; de los libros y periódicos que se editaron en la segunda mitad del siglo XVIII y circularon hasta estos territorios; de los criollos que se desplazaron hasta Europa y volvieron, trayendo consigo las ideas del viejo continente ${ }^{58}$, así como de los peninsulares que inmigraron tardíamente

${ }^{56}$ Diana Soto Arango, Mutis, filósofo y educador. Una muestra de la realidad educativa americana del siglo XVIII (Tunja: Universidad Pedagógica y Tecnológica de Colombia, 2009), 61-84.

${ }^{57}$ Campo del Pozo, "Modernización de los estudios", 44.

58 Juan Manuel Pacheco, La Ilustración en el Nuevo Reino (Caracas: Universidad Católica Andrés Bello, 1975), 9; Soto Arango, Mutis educador, 37; Carlos Arnulfo Rojas Salazar, "Una corriente de pensamiento: ¿liberalismo neogranadino?, en Las Españas y las Américas: los españoles de 
a las nuevas tierras y estaban imbuidos del espíritu ilustrado español ${ }^{59}$. No obstante, hay que anotar que la Ilustración neogranadina se centró en la explotación económica del territorio a través de las ciencias positivas, para lo cual las autoridades consideraron que era necesaria la modernización de la educación que recibían las elites criollas, de tal manera que se les instruyera en conocimientos útiles que posibilitaran mayor eficacia en el aprovechamiento de los recursos naturales del Virreinato ${ }^{60}$.

La generación inicial de criollos educada dentro del movimiento ilustrado recibió las ideas de la modernidad de la corriente tradicionalista de la llustración española, que va desde el benedictino Feijoo hasta el jurista Jovellanos y se preocupaba por dar el paso a la modernidad sin perder de vista el peso de la tradición hispana. Feijoo había planteado en sus escritos una nueva relación entre fe y razón, afirmando que la religión debía sostenerse sobre el conocimiento de las ideas filosóficas y no sobre la ignorancia de estas, el oscurantismo y el fanatismo. Por su parte, Jovellanos veía la necesidad de incrementar los conocimientos útiles en detrimento del escolasticismo. Igualmente, para este ministro de Carlos III, la instrucción pública debía ser el pilar de la prosperidad social de la monarquía hispánica ${ }^{61}$. No obstante, Jovellanos también recalcó como necesidad pública la enseñanza de la religión y la moral cristiana: “QQué hará ésta -la educación-con formar a los jóvenes en las virtudes del hombre natural y civil, si les deja ignorar las del hombre religioso?" ${ }^{62}$. Mientras que la corriente más radical de la Ilustración, infundida del enciclopedismo francés, penetró muy lentamente en el Virreinato, a manera de contrabando y, tan solo llegó a influir de manera decisiva a la generación siguiente de criollos neogranadinos, caracterizada por realizar la independencia política del Virreinato ${ }^{63}$.

amboshemisferios ante la crisis de la independencia, ed. Gonzalo Buitrón Prada (Cádiz: Servicio de Publicaciones de la Universidad de Cádiz, 2012), 137.

${ }^{59}$ Silva, Los ilustrados, 44.

${ }^{60}$ Rojas Salazar, “Una corriente de pensamiento”, 137.

${ }^{61}$ Álvaro Pablo Ortiz Rodríguez, Reformas borbónicas. Mutis catedrático, discípulos y corrientes ilustradas, 1750-1816 (Bogotá: Centro Editorial Rosarista, 2003), 7-9.

62 Pacheco, La Ilustración, 8.

${ }^{63}$ María Teresa Cristina, "La literatura en la conquista y en la colonia”, en Manual de historia de Colombia, Tomo I, Ed. Jaime Jaramillo Uribe (Bogotá: Ministerio de Cultura- Tercer Mundo Editores, 1999), 568. 
José Celestino Mutis hizo parte del grupo de intelectuales ilustrados que intentó y reformó, durante el reinado de Carlos III, algunos de los aspectos económicos, educativos y administrativos del imperio hispánico, teniendo como parámetro el estudio de las ciencias útiles ${ }^{64}$. Mutis se dirigió al Virreinato neogranadino como médico personal del virrey Messía de la Cerda en 1760. Estando en él, hizo sentir su curiosidad hacia las ciencias empíricas. En 1762 presentó la primera cátedra de matemáticas del Virreinato en el Colegio de Nuestra Señora del Rosario ante los funcionarios de la audiencia, el cabildo y la sociedad santafereña ${ }^{65}$. Aunque el rector del claustro le había sugerido insistentemente que impartiera la de medicina, Mutis consideró más provechoso educar en los principios matemáticos a una generación de criollos que, al servicio de la Corona, se encargara de las transformaciones administrativas y económicas deseadas por la metrópoli. Asimismo, influido por su espíritu renovador, Mutis colaboró en la elaboración de los cuatro planes de estudios avanzados, realizados en el Virreinato durante la segunda mitad del siglo XVIII ${ }^{66}$.

Durante su segunda estadía en Santafé, entre 1770 y 1776, Mutis defendió la tesis copernicana en el Colegio de Nuestra Señora del Rosario afirmando que el centro del sistema planetario era el sol y no la tierra, como lo sostenía la Iglesia, basada en el pasaje bíblico de Josué 10: 12-13. Inmediatamente, los padres dominicos de la Universidad de Santo Tomás lo denunciaron ante el Tribunal de la Inquisición, al considerar que sus enseñanzas atentaban contra los preceptos de la fe cristiana. No obstante, Mutis fue respaldado por el virrey Guirior, quien apoyaba la reforma educativa emprendida en el Virreinato por el fiscal Antonio Moreno y Escandón. Este funcionario pretendía crear una universidad pública en la que se enseñaran las cátedras de matemáticas y ciencias positivas ${ }^{67}$. La presencia de José Celestino Mutis supuso un proceso de transformación y modernización tanto en la forma como se impartía la

${ }^{64}$ Sobre la acción de José Celestino Mutis en el Virreinato neogranadino véase Silva, Los ilustrados, 48.

${ }^{65}$ Sobre un curso de matemáticas en el virreinato de la Nueva Granada anterior a 1762, véase Pacheco, La Ilustración,10-11; Silva, Los ilustrados, 55.

${ }^{66}$ Rojas Salazar, “Una corriente de pensamiento”, 137-138. Los cuatro planes referidos son: el de Moreno y Escandón, el de Caballero y Góngora, el de Eloy Valenzuela y el de Medicina del padre Isla.

${ }^{67}$ Anthony McFarlane, Colombia antes de la independencia: economía, sociedad y política bajo el dominio Borbón (Bogotá: Banco de la República, 1997), 412. 
educación en los colegios y universidades virreinales como en la manera en que se llevaba a cabo la investigación científica.

A este esfuerzo modernizador de la educación contribuyeron significativamente los virreyes de las tres últimas décadas del siglo XVIII. El primero de estos fue el jefe de la Real Armada, Manuel Guirior (1773-1776), quien aprobó el plan de estudios superiores diseñado por el fiscal de la audiencia Francisco Antonio Moreno y Escandón. El nuevo plan de estudios implantaba el espíritu de la Ilustración y el racionalismo europeo en el virreinato, dado que, en contra de la escolástica, propagaba la enseñanza de las ciencias positivas y el método experimental ${ }^{68}$.

El plan de estudios del fiscal Moreno y Escandón tuvo como modelo la modificación curricular que Pablo de Olavide implantó en la Universidad de Sevilla en 1768. Dirigido a cambiar el pensum educativo de los colegios mayores de Santafé, estipuló las disciplinas que debían ser enseñadas obligatoriamente en ellos, su contenido, su intensidad horaria, los textos de guía y de consulta y el mecanismo de evaluación ${ }^{69}$; con ello, la Corona interfería y a la vez ponía control en la educación que la Iglesia brindaba a las elites neogranadinas.

El nuevo plan reglamentó para la carrera de filosofía en el primer año las cátedras de lógica, aritmética, álgebra, geometría y trigonometría; en el segundo, la cátedra de física y, en el tercero, la cátedra de metafísica. Para la carrera de teología determinó la cátedra de estudio de libros sagrados -Antiguo Testamento, salterio, evangelios, Hechos de los apóstoles, cartas paulinas--, la de geografía y contexto histórico bíblico, además de la de lecturas conciliares. Estas cátedras se distribuían durante los cinco años que duraba la formación. Para los estudios de jurisprudencia se estableció la cátedra de derecho romano durante los dos primeros años, mientras que, para el tercero, derecho canónico $\mathrm{y}$, para el cuarto y quinto, instituciones canónicas. El plan no hizo ninguna mención a la carrera de medicina, posiblemente porque no se contaba con estudios formales en Santafé ni mucho menos con expertos en esta materia ${ }^{70}$. De igual manera, con el fin de que los cursos empezaran y terminaran todos los años, el plan prescribió trece catedráticos para cada uno de los colegios: tres de filosofía, cinco de teología y cinco de jurisprudencia; además, un sistema de

68 Javier Ocampo López, Breve historia de Colombia (Caracas: Academia Nacional de Historia, 1989), 180-181; Rojas Salazar, “Una corriente de pensamiento”, 138.

${ }^{69}$ Torrejano Vargas, “Perfil de la educación”, 288-290.

${ }^{70}$ Diana Soto Arango, La reforma del plan de estudios del fiscal Moreno y Escandón, 1774-1779

(Bogotá: Centro Editorial Universidad del Rosario, 2004), 102-139. 
evaluación y promoción escolar. Así, dictaminó que la aprobación de un año escolar dependía de la superación del examen al final. Quien reprobara dicho examen repetiría el curso; y, en caso de que lo suspendiera por segunda vez, sería expulsado definitivamente del colegio ${ }^{71}$.

En conclusión, Moreno y Escandón buscó con la reforma educativa que la universidad neogranadina estuviera bajo el control de la Corona y administrada por el sector civil. Su método debía ser la experimentación de las ciencias positivas en contraposición al silogismo escolástico. Y se debían incluir nuevas cátedras en el pensum educativo, tales como las matemáticas, física y geografía ${ }^{72}$. Sin embargo, pronto encontró fuertes detractores tanto dentro de las órdenes religiosas, como por parte de las autoridades académicas tradicionales, las cuales, moviendo influencias en el virreinato y en la corte de Madrid, lograron derogar las nuevas políticas educativas. El plan de estudios estuvo vigente solamente entre 1774 y 1778 ; luego, la Junta Superior de Estudios del virreinato, presidida por el visitador general Francisco Gutiérrez de Piñeres y con la presencia del fiscal Moreno y Escandón, estableció uno distinto. Aunque este nuevo plan conservó la preeminencia de las ciencias naturales y las matemáticas y mantuvo el pensum de jurisprudencia, al mismo tiempo, hizo regresar los estudios filosóficos y teológicos al método escolástico y los patrones tradicionales puesto que, una vez más, siguieron la Summa Theologiae de Santo Tomás y las Sententiae de Pedro Lombardo ${ }^{73}$. Por consiguiente, la marcha atrás de la reforma universitaria en el Virreinato neogranadino solo fue en relación a los planes de estudios de las carreras de filosofía y teología y no en relación al plan de estudios de jurisprudencia, al que además se le añadió la asignatura de derecho público, natural y de gentes, siguiendo el manual Elementa iurisnaturae et gentium (1738); obra del filósofo y jurista alemán Johann Gottlieb Heinnecio, uno de los mayores representantes del derecho natural racionalista. Esta asignatura permaneció en el pensum universitario neogranadino hasta $1795^{74}$, educando a una generación de criollos en los ideales políticos ilustrados. La aportación fundamental de Heinnecio consistió en convertir el derecho natural en jurisprudencia, es decir, en transformar lo ideal en aplicable, en hacer

${ }^{71}$ Torrejano Vargas, "Perfil de la educación”, 290.

72 Soto Arango, “Aproximación histórica”, 104.

${ }^{73}$ Fernando Betancourt Serna, "Universidad ilustrada neogranadina e independencia de Colombia (1810-2010)”, Revista Historia de la Educación Latinoamericana, 14 (2010): 88.

${ }^{74}$ Fue abolida por la Real Orden del 31 de julio de 1794. Véase Betancourt Serna, "Universidad ilustrada neogranadina”, ) 83. 
de la teoría una praxis. Su obra ordenó los planteamientos de Hugo Groccio, Samuel Pufendorf y Christian Tomasius ${ }^{75}$.

Moreno y Escandón también abogó por la creación de una universidad pública en un intento por quitarle el monopolio de expedir títulos universitarios a la Orden de Predicadores. Para ello, propuso que se nombrara un director que no perteneciera a su claustro; que los exámenes de la obtención de grados fueran realizados por los catedráticos de los colegios del Rosario y San Bartolomé, dado que hasta entonces esta tarea era desempeñaba por los lectores del Convento de Santo Domingo; además, que todos los empleados de la universidad fueran elegidos por el claustro de los graduados, claustro que, por otra parte, también debía reunirse para resolver todos los asuntos graves de la universidad. No obstante, este proyecto no encontró espacioy se congeló, al igual que el proyecto de reforma de los pénsums de los colegios mayores de Santafé ${ }^{76}$.

El único proyecto educativo de Moreno y Escandón que halló una respuesta favorable en el Virreinato fue la fundación de una biblioteca pública, la cual se inauguró oficialmente en Santafé a principios de 1777. Su principal acervo bibliográfico provino de los libros decomisados a la Compañía de Jesús después de su expulsión de 1767. Así, del colegio de Santafé se llevaron a la biblioteca más de 4.000 títulos, mientras que de los distintos colegios provinciales cerca de $8.000^{77}$. Todas las medidas que Moreno y Escandón trató de implementar en la Nueva Granada iban encaminadas a la formación de un nuevo grupo social de condición seglar y desligado lo más posible de la Iglesia ${ }^{78}$.

El arzobispo Antonio Caballero y Góngora fue otro de los virreyes que propagó el espíritu de la Ilustración en la Nueva Granada. Una vezfue nombrado virrey en 1783, se encaminó a recuperar el apoyo de la nueva generación de criollos. Dos años atrás a su nombramiento y como fruto del levantamiento de los comuneros de El Socorro, se había producido desconfianza hacia los neogranadinos entre las autoridades metropolitanas. En el periodo de Caballero y Góngora, la preparación y la difusión de las ideas modernas educativas, científicas y económicas tuvieron desde su inicio una doble intención. Por un lado, razones económicas, derivadas del ideal ilustrado de mayor productividad y, por otro, un cálculo político, pues el apoyo del arzobispo-virrey a la reforma

\footnotetext{
${ }^{75}$ Betancourt Serna, 89.

${ }^{76}$ Pacheco, La Ilustración, 111.

77 Silva, Los ilustrados, 82.

${ }^{78}$ Uribe-Urán, Vidas honorables, 81.
} 
educativa sugería su interés por renovar, dentro del aparato burocrático virreinal, a los criollos que habían participado en el levantamiento comunero ${ }^{79}$.

Pese a la intención del arzobispo, el espíritu de la Ilustración, que había calado profundamente en un grupo de intelectuales neogranadinos, buscó desde principios del siglo XIX, además de las reformas económicas, reformas políticas. La formación académica recibida por varias generaciones de criollos a lo largo del siglo XVIII posibilitó esta realidad. Los avances de los conocimientos científicos, el desarrollo del derecho de gentes y el uso de metodologías empíricas contribuyeron notablemente al cuestionamiento del statu quo tradicional, más aún cuando la monarquía hispana entró en crisis debido a las invasiones napoleónicas. Este nuevo escenario internacional fue propicio para que los criollos neogranadinos pusieran en práctica el bagaje filosófico de la Ilustración en sus discursos y acciones políticas, así como las de su correspondiente sucesor ideológico, el liberalismo hispano ${ }^{80}$. Durante la crisis de la monarquía hispana, los criollos neogranadinos, formados tanto en los colegios jesuitas y agustinos como a través de los canales oficiales y no oficiales de la Ilustración, ayudaron a cimentar epistemológicamente y a realizar efectivamente la revolución neogranadina. La independencia política de la Nueva Granada obedece en gran parte a las reformas educativas emprendidas en primera instancia por jesuitas y agustinos en sus colegios y universidades a lo largo del siglo XVIII, así como a su posterior afianzamiento a través de los nuevos planes de estudios introducidos por los funcionarios ilustrados del Estado hispano ${ }^{81}$.

\footnotetext{
${ }^{79}$ McFarlane, Colombia antes de la independencia, 411; Rojas Salazar, "Una corriente de pensamiento", 138-139.

${ }^{80}$ Rojas Salazar, 142.

${ }^{81}$ Entre los alumnos que se formaron en el Colegio Seminario de Popayán en el tiempo de la reforma educativa se cuentan Francisco Antonio Zea, Camilo Torres y Tenorio, Jerónimo Torres y Tenorio, José Ignacio de Pombo, Manuel Antonio Pombo, Manuel María Arboleda Antonio Arboleda, Andrés Marcelino Pérez de Valencia, Santiago Pérez Valencia, Toribio Migüez, Joaquín de Caicedo, Manuel José Caicedo, Francisco Antonio Ulloa, José María Cabal, José María Grueso, Manuel María Quijano, Manuel María Urrutia, Manuel José Hurtado, Nicolás Hurtado y Francisco José de Caldas, quienes desempeñaron papeles importantes en los bandos que se formaron en las guerras de independencia neogranadinas. Véase Rojas Salazar, "Educación y ciencia”, 83.
} 


\section{Conclusiones}

La independencia de la Nueva Granada no obedece a una única causa, sino a múltiples y de toda índole. Una de ellas, y de gran calado, fue la reforma educativa que desmontó el silogismo aristotélico tomista en los colegios y universidades jesuitas y agustinas y, al mismo tiempo, introdujo el conocimiento de la nueva ciencia moderna. Esta reforma educativa contribuyó significativamente a la asunción de una conciencia propiamente americana en oposición a la europea; así mismo, ayudó a sustentar epistemológicamente los discursos políticos neogranadinos, que al principio reclamaban igualdad frente a lo peninsular y, posteriormente, la independencia jurídica del territorio.

Al lado de las reformas educativas emprendidas por jesuitas y agustinos en sus colegios y universidades a lo largo del siglo XVIII, se produjo la llegada de la Ilustración hispana a la Nueva Granada. Esta corriente de pensamiento, promovida desde arriba por el Estado hispano, buscaba mayor efectividad en la explotación de los recursos naturales y mineralógicos del territorio. A pesar de este propósito económico, el espíritu ilustrado penetró profundamente otras esferas de la sociedad neogranadina, como la cultura y la política, y fue junto con las reformas educativas del siglo XVIII el principal sustento ideológico de los discursos políticos de los agentes de la independencia. El otro sustento epistemológico, nacido de su desarrollo, fue el liberalismo hispano, el cual entró en escena tras la Revolución francesa y en el marco de las invasiones napoleónicas a la península.

Finalmente, como lo advirtió François-Xavier Guerra, la primera generación de criollos formados bajo los principios de la Ilustración puso su esperanza en el poder monárquico como motor transformador de la realidad; para ellos, primero debía producirse la evolución social antes que la política. Entretanto, la última generación de criollos ilustrados invirtió el orden de la ecuación. Pues para estos, en primera instancia debía producirse la reforma política y, tras ella, la reforma social ${ }^{82}$. Son estos últimos los ideólogos y agentes de la independencia del territorio de la Nueva Granada, hoy República de Colombia.

${ }^{82}$ François-Xavier Guerra, Modernidad e independencia.Ensayos sobre las revoluciones hispánicas (México D. F.: Editorial Mapfre-Fondo de Cultura Económica, 1992), 39. 


\section{Referencias bibliográficas}

\section{Fuentes primarias}

Recopilación de leyes de los reynos de Indias: mandadas a imprimir y publicar por la magestad católica del rey Don Carlos II,nuestro señor. Tomo I, Libro I, Título Vientidós, De las Universidades y estudios generales y particulares de las Indias (Madrid: Julián de Paredes 1681). http://www.gabrielbernat.es/espana/leyes/rldi/rldi.html

"Praxis de los estudios para el colegio de Quito sacada de varias órdenes que han dejado acerca de esto el P. Rodrigo Figueroa Visitador y los padres provinciales de esta provincia; los cuales han reducido a método el $P$. Hernando Cavero provincial de ella, habiéndolos primero consultado con el padre rector y sus consultores y con los maestros de este colegio, Quito 15 de abril de 1666". En Historia de la Compañía de Jesús en la Antigua Provincia de Quito: 1570-1774, editado por José Jouanen. Quito: Editorial Ecuatoriana, 1941, 569-593.

\section{Fuentes secundarias}

Betancourt Serna, Fernando. "Universidad ilustrada neogranadina e independencia de Colombia (1810-2010)". Revista Historia de la Educación Latinoamericana, 14 (2010): 83-99.

Campo del Pozo, Fernando. "Modernización de los estudios agustinianos en Santafé de Bogotá por fray Diego Francisco Padilla a finales del siglo XVIII”. Revista Historia de la Educación Latinoamericana, n.. 2 (2000): 37-50.

Campo del Pozo, Fernando. "Las reformas universitarias en los agustinos durante la época colonial en Latinoamérica”. En Estudios sobre la universidad latinoamericana. De la colonia al siglo XXI, editado por Diana Soto Arango, Manuel Lucena Samoral y Carlos Rincón. Tunja: Universidad Pedagógica y Tecnológica de Colombia, 2004, 15-27.

Cobos, Ricardo. La formación intelectual en los colegios de la Compañía de Jesús. Madrid: Dirección General de Enseñanza Media, s/f.

Cristina, María Teresa. "La literatura en la conquista y en la colonia". En Manual de historia de Colombia, Tomo I, editado por Jaime Jaramillo Uribe. Bogotá: Ministerio de Cultura - Tercer Mundo Editores, 1999, 493-592.

Del Rey Fajardo, José. Expulsión, extinción y restauración de los jesuitas en el Nuevo Reino de Granada (1767-1815). Bogotá: Pontificia Universidad Javeriana, 2014.

Del Rey Fajardo, José. La enseñanza de las humanidades en los colegios jesuíticos neogranadinos (1604-1767). Bogotá: Pontificia Universidad Javeriana, 2005.

Del Rey Fajardo, José y Germán Marquínez Argote. La enseñanza de la filosofía en la Universidad Javeriana colonial (1623-1767). Bogotá: Pontificia Universidad Javeriana, 2010.

Fajardo, Negrín y Ciordia Vergara. La educación como dimensión práctica: una respuesta histórica. Madrid: Editorial Universitaria Ramón Areces, 2010. 
Gálvez Ramírez, Álvaro. Universidad Santo Tomás. 1580-1980. 400 años. Bogotá: Universidad Santo Tomás, 1980.

Gómez Hoyos, Rafael. La revolución granadina de 1810. Ideario de una generación y una época, Tomos I y II - 1781-1821. Bogotá: Editorial Temis, 1962.

Groot, José Manuel. Historia eclesiástica y civil de la Nueva Granada. Bogotá: Editorial Cosmos, Biblioteca de Autores Colombianos, 1956.

Guerra, François-Xavier. Modernidad e independencia. Ensayos sobre las revoluciones hispánicas. México D. F.: Editorial Mapfre-Fondo de Cultura Económica, 1992.

Guillén de Iriarte, María Clara. Nobleza e hidalguía en el Nuevo Reino de Granada. Colegio Mayor de Nuestra Señora del Rosario, Tomos I y II. Santafé de Bogotá: Ediciones Rosaristas, 1994.

Hernández de Alba, Guillermo. Aspectos de la cultura en Colombia. Bogotá: Biblioteca Popular de Cultura Colombiana, 1947.

Hernández de Alba, Guillermo. Crónica del muy ilustre Real Colegio Mayor de Nuestra Señora del Rosario, 2 vols. Bogotá: Editorial Centro, 1938.

Jaramillo Mejía, William. Real Colegio Mayor y Seminario de San Bartolomé nobleza e hidalguía-. Colegiales de 1605 a 1820. Bogotá: Instituto Colombiano de Cultura Hispánica, 1996.

Jouanen, José, ed. Historia de la Compañía de Jesús en la Antigua Provincia de Quito: 1570-1774. Quito: Editorial Ecuatoriana, 1941.

McFarlane, Anthony. Colombia antes de la independencia: economía, sociedad y política bajo el dominio Borbón. Bogotá: Banco de la República, 1997.

Ocampo López, Javier. Breve historia de Colombia. Caracas: Academia Nacional de Historia, 1989.

Ortiz Rodríguez, Álvaro Pablo. Reformas borbónicas. Mutis catedrático, discípulos y corrientes ilustradas, 1750-1816. Bogotá: Centro Editorial Rosarista, 2003.

Pacheco, Juan Manuel. La Ilustración en el Nuevo Reino. Caracas: Universidad Católica Andrés Bello, 1975.

Pacheco, Juan Manuel. Los jesuitas en Colombia, Tomos I y III. Bogotá: Editorial San Juan Eudes, 1959.

Quevedo Emilio y Duque Camilo. Historia de la cátedra de medicina. 1653-1865. Bogotá: Centro Editorial de la Universidad del Rosario, 2002.

Restrepo, Daniel. El Colegio de San Bartolomé I. El colegio a través de nuestra historia. Bogotá: Sociedad editorial, 1928.

Rojas Salazar, Carlos Arnulfo. "Educación y ciencia en la ciudad de Popayán antes de los procesos de independencia hispanoamericanos". En De imperios a naciones en el mundo ibérico, editado por Alberto Baena Zapatero y Izaskun Álvarez Cuartero. Madrid: Ediciones Doce Calles, 2019, 75-91.

Rojas Salazar, Carlos Arnulfo. "Amos del oro, siervos del rey, ciudadanos del reino. La elite de Popayán y los procesos de independencia hispanoamericanos, 18081820”. Tesis doctoral, Universidad de Salamanca, 2015.

Rojas Salazar, Carlos Arnulfo. "Una corriente de pensamiento: ¿liberalismo neogranadino? En Las Españas y las Américas: los españoles de ambos hemisferios ante la 
crisis de la independencia, editado por Gonzalo Buitrón Prada. Cádiz: Servicio de Publicaciones de la Universidad de Cádiz, 2012, 135-146.

Silva, Renán. Los ilustrados de Nueva Granada. Genealogía de una comunidad interpretativa, 2. ${ }^{a}$ ed. Medellín: Fondo Editorial Universidad Eafit - Banco de la República, 2008.

Silva, Renán. Universidad y sociedad en el Nuevo Reino de Granada. Santafé de Bogotá: Banco de la República, 1992.

Soto Arango, Diana. Mutis, filosofo y educador. Una muestra de la realidad educativa americana del siglo XVIII. Tunja: Universidad Pedagógica y Tecnológica de $\mathrm{Co}^{-}$ lombia, 2009.

Soto Arango, Diana. Mutis educador de la élite neogranadina. Tunja: Universidad Pedagógica y Tecnológica de Colombia, 2005.

Soto Arango, Diana. "Aproximación histórica a la universidad colombiana". Revista Historia de la Educación Latinoamericanas, n.. 7 (2005): 101-138.

Soto Arango, Diana. La reforma del plan de estudios del fiscal Moreno y Escandón, 17741779. Bogotá: Centro Editorial Universidad del Rosario, 2004.

Torrejano Vargas, Rodrigo Hernán. "Perfil de la educación universitaria colonial a finales del siglo XVIII". Revista Diálogo de Saberes, n.․ 31 (2009): 283-298.

Uribe Ángel, Jorge Tomás. Historia de la enseñanza en el Colegio Mayor del Rosario, 1653-1767. Bogotá: Centro Editorial de la Universidad del Rosario, 2003.

Uribe-Urán, Víctor Manuel. Vidas honorables: abogados,familias y políticasen Colombia. Medellín: Fondo Editorial Universidad Eafit, 2008.

Vargas Sáez, Pedro. Historia del Real Colegio y Seminario de San Francisco de Asís de Popayán. Popayán: Editorial ABC, 1945. 